\title{
A Gestão da comunicação interna das instituições públicas: um recurso esquecido
}

\author{
Maria Francisca Magalhães Nogueira*
}

\begin{abstract}
Resumo
Analisa a gestão da comunicação interna das instituições públicas em face das mudanças ocorridas no cenário nacional e internacional. Sugere mudanças significativas no processo de gerenciamento da comunicação de forma estratégica, com vistas a possibilitar o desenvolvimento de uma nova visão da prática gerencial nas instituições públicas. Aponta a necessidade de os profissionais de comunicação dos órgãos públicos desvencilharem-se do modelo burocrático e tradicional da filosofia vigente nas instituições, a fim de promover uma comunicação integrada e consensuada em todos os níveis e serviços. Provavelmente, a contribuição que esse profissional poderá prestar aos diretores, aos gerentes, aos chefes e a todo o corpo de funcionários está na conscientização de todas as necessidades de comunicação demonstradas ao longo do texto.

Palavras-chave: comunicação interna; gestão pública - mudanças; instituições públicas - comunicação interna.
\end{abstract}

\section{Introdução}

O desafio do desenvolvimento, os avanços técnico-científicos e tecnológicos, a globalização vêm demandando das instituições públicas novas respostas no que se refere à melhoria dos serviços prestados à sociedade. $\mathrm{O}$ ambiente contemporâneo comporta necessidades que o modelo burocrático de organização já não atende plenamente. Esse modelo - que se desenvolveu em condições diferentes das atuais, em uma sociedade de ritmo mais lento, em um tempo em que o

* Mestre em Comunicação e Profa. da Faculdade de Comunicação e Biblioteconomia da UFG.

Comun. Inf., v. 4, n. 1/2, p.121-131, jan./dez. 2001 
trabalho era muito mais braçal do que intelectual e no qual somente as pessoas em postos hierarquicamente superiores dispunham de informações suficientes para decidir - não foi extirpado de nossas organizações. Como dizem Osborne e Gaebler (1998, p. 16), "em certas circunstâncias, as instituições burocráticas ainda funcionam. Se o ambiente é estável, a tarefa a realizar, relativamente simples, e todos os clientes querem o mesmo serviço, sem que a qualidade se torne crítica, a burocracia pública tradicional pode ser eficaz".

Durante muito tempo esse modelo burocrático funcionou, porque resolvia problemas fundamentais: dava segurança e estabilidade, criava empregos e fornecia serviços elementares. Esse quadro mudou e as administrações públicas vêm cada vez mais sendo pressionadas a produzir serviços de qualidade, a oferecer opções diferenciadas de informações e a tornar o processo de trabalho imbuído de significado para os servidores que respondem às necessidades do público.

Para isso, as administrações públicas deparam-se com problemas de ordem legal, cultural e gerencial. A dimensão legal

refere-se aos dispositivos legais constitucionais e infra-constitucionais, que se colocam como obstáculo à modernização de gestão do aparelho do Estado, em consonância com os padrões de eficiência e qualidade requeridos no processo da reconstrução do mesmo. A dimensão cultural se refere aos valores patrimoniais e principalmente burocráticos com os novos valores gerenciais e modernos na administração pública brasileira. A dimensão gerencial se refere às práticas administrativas (ENAP, 1998, p. 2).

Neste artigo focaremos a atenção apenas nas dimensões cultural e gerencial, pelo fato de a cultura e a gestão constituírem-se fontes geradoras de interferência no processo de comunicação interna e externa. Existe uma relação direta entre os problemas que o ambiente interno coloca para a organização e, consequentemente, para os procedimentos pelos quais ela tende a ser dirigida. Os modos de gerir a instituição vão influenciar a concepção e a forma de exercício da comunicação interna.

\section{Os comunicadores e a cultura das instituições públicas}

Os reflexos internos das mudanças externas às instituições têm sugerido novas formas de administrar. Segundo Gaino (1989, p. 18), o Comun. Inf., v. 4, n. 1/2, p.121-131, jan./dez. 2001 
modelo "mecanicista foi totalmente orientado para a eficiência, que é uma medida individual. Temos que procurar agora a eficácia, que é adulta e coletiva, e que exige o compartilhar com responsabilidade, integrando informações". Os caminhos perseguidos pelas instituições são muitos e nesse processo de buscas de alternativas e soluções para os muitos problemas vivenciados surgem novas teorias.

As modernas teorias e práticas administrativas vêm munindo organizações com métodos de planejamento e gerenciamento sistemáticos, fundamentados em diagnósticos que permitem formular soluções planejadas estrategicamente. A administração estratégica tem-se mostrado eficaz por proporcionar à instituição o vislumbre de um norte que deve ser perseguido de forma global. A visão estratégica ainda permite exercer influência nas atividades internas e externas à organização. Segundo Cabrera e Gaino (1989, p. 15), "o sucesso desse processo depende da capacidade da organização de engajar todos os seus colaboradores no mesmo esforço, na mesma direção, com intensidade e motivação suficientes para estabelecer o processo sinérgico que garantirá o resultado almejado no tempo e no espaço previstos".

Diante dessas mudanças, os profissionais de comunicação das administrações públicas - Relações Públicas e Assessores de Imprensa, mesmo os que buscam fundamentar suas ações comunicativas visando alcançar resultados que os usuários e a sociedade vêm demandando são desafiados a demonstrar as amplas possibilidades de a comunicação oferecer ajuda na interpretação da realidade e na revisão crítica dos valores da cultura organizacional. Uma das maiores dificuldades dos setores encarregados do planejamento, da gestão e da execução das ações de comunicação, porém, tem consistido na interpretação do ambiente interno.

Os profissionais de comunicação deparam-se com dificuldades inerentes à estrutura organizacional, além dos valores impregnados na cultura da instituição. Os valores de instituições com fortes tradições burocráticas influenciam e dificultam a promoção de uma comunicação que vise a instituição como um todo. Valores patrimoniais e principalmente burocráticos antagonizam-se com os novos valores gerenciais e modernos.

Muitas vezes, os comunicadores se vêem diante de interesses antagônicos à concepção estratégica de comunicação para a instituição, como, por exemplo, o interesse de chefes em divulgar determinados

Comun. Inf., v. 4, n. 1/2, p.121-131, jan./dez. 2001 


\section{4}

projetos e ações dos órgãos ou mesmo em promover iniciativas individuais, com o intuito de promoção pessoal. Além dessas dificuldades, pode-se enumerar a forte tradição das instituições em divulgar, somente via Assessoria de Imprensa e Publicidade Institucional, a falta de sinergia entre as mais diversas áreas da comunicação atuantes nos órgãos públicos, e a pouca tradição dos profissionais de comunicação em planejar os relacionamentos e as ações institucionais, a fim de tornálas contínuas e duradouras.

Todos esses motivos remetem ao reconhecimento da necessidade de os comunicadores compreenderem a mentalidade das instituições públicas. Em outras palavras, sua cultura organizacional, os valores e crenças vigentes, difíceis de serem mudados.

As Assessorias de Comunicação são comumente convocadas a "repassar" idéias inovadoras, quando as instituições, no intuito de acompanhar os modismos, promovem alterações de alcance efêmero e superficial. Implantam-se programas de qualidade sem prévio diagnóstico da doutrina que tem inspirado e dado rumo às ações dos órgãos públicos, desprezando-se experiências acumuladas ao longo de anos. Nessas ocasiões, elaboram-se projetos de comunicação para um público interno que reage das mais diversas formas. Determinados grupos fazem de conta que entenderam, que aceitaram e que estão de acordo com os novos empreendimentos e procedimentos. Outros aglomeram-se e formam feudos, como forma de defesa contra o desconhecido, contra a própria instituição e contra as reclamações dos usuários.

Há muito a avançar, no que se refere à gestão dos processos comunicativos internos, tendo em vista a escassa participação dos diversos grupos que formam o público interno. A falta de participação tem várias origens e, dentre elas, um modelo de organização que abre um amplo leque à fragmentação. Podemos citar o exemplo das universidades públicas federais, em que a dificuldade de integração da comunidade universitária tem dificultado a disseminação do que ela mesma produz.

O ambiente interno pode ser analisado, segundo Oliveira (1988, p.82-88), mediante o conhecimento da estrutura e da cultura organizacional. A estrutura organizacional é a responsável pela atividade da instituição e se expressa no organograma, nas atribuições, nos manuais de normas e procedimentos, nas rotinas de trabalho e nas descrições de cargos; a cultura organizacional se manifesta pelos valo-

Comun. Inf., v. 4, n. 1/2, p.121-131, jan./dez. 2001 
res e crenças impregnados nos comportamentos individuais e coletivos. A cultura das instituições pode ser interpretada utilizando-se alguns procedimentos, como diz Oliveira (1988, p. 82-88):

\begin{abstract}
Olhe o ambiente físico da organização, verifique como a organização trata os estranhos, entreviste pessoas típicas da organização; observe como as pessoas usam o tempo, investigue como acontece o recrutamento, a seleção e a admissão das pessoas, observe como se progride nessa organização, verifique quanto tempo as pessoas permanecem na organização, observe o conteúdo das conversas especialmente na horas das refeições, preste atenção ao relacionamento entre as pessoas, no ambiente de trabalho.
\end{abstract}

O perfil da cultura organizacional pode ser dimensionado em todos os aspectos da organização. Nas palavras de Srour (1998, p. 167), esse perfil pode ser demonstrado, pois "a arquitetura do ambiente, os móveis e os quadros embutem algo que os gestos desenham. As cores, os movimentos do pessoal e os equipamentos evocam o que as palavras celebram. E de forma curiosa, os agentes individuais, habitualmente tão diversos entre si, assemelham-se nos ritmos e jeitos".

Então, diante de uma cultura tradicional, rígida e demasiadamente burocrática de muitos órgãos públicos, os comunicadores necessitam de um esforço suplementar para conhecer profundamente $o$ ambiente em que operam. Para isso, as técnicas e as estratégias de comunicação com seus instrumentos são suas aliadas, permitindo-lhes identificar ameaças, falhas e oportunidades. Detectar o modelo de gestão em voga torna-se fundamental, na medida em que esse modelo constitui-se, como diz Beuren (1998, p. 36), na "representação teórica do processo de administrar, a fim de garantir a consecução da missão para a qual foi concebida".

Gerir significa desenvolver estratégias financeiras, de recursos humanos, de comunicação etc., a fim de que a instituição cumpra sua missão, assegurando-se continuidade. Pode-se, assim, dizer que o modelo de gestão adotado pelas instituições exercem forte influência na concepção de comunicação, em virtude de as crenças e os valores dos dirigentes se transformarem em convicções influenciadoras do comportamento de todas as pessoas que compõem o corpo de servidores.

Comun. Inf., v. 4, n. 1/2, p.121-131, jan./dez. 2001 
Beuren (1998, p. 39) ressalta que

\begin{abstract}
a concepção do sistema de informações é dependente do sistema de gestão ao qual vai servir de suporte. Desse modo, os esforços, na arquitetura e no desenvolvimento do sistema de informações, devem ser concentrados na identificação das informações necessárias ao processo de gestão empresarial e na determinação dos subsistemas que devem gerá-las. Isto sugere que haja integração do sistema de informação com o sistema organizacional.
\end{abstract}

O diagnóstico da comunicação, nesses momentos, pode fundamentar os atos comunicativos, permitindo levantar dados originários da conduta administrativa, ajudando a compreender, a analisar e a propor alternativas de comunicação para alterar os relacionamentos hierárquicos estabelecidos e transformar as ações e os procedimentos adotados. O diagnóstico possibilita dar um tratamento adequado aos problemas originários da comunicação burocrática, permitindo que os dirigentes reformulem posturas e atitudes e criem novas alternativas para informarem, esclarecerem e relacionarem-se com seus públicos. O planejamento da comunicação burocrática constitui um mecanismo eficaz para o processamento de informações importantes, no âmbito das funções administrativas. Na maioria das vezes, essa conduta em relação à comunicação burocrática - que viabiliza todo o sistema burocrático - é relegada e tida como de menor relevância.

Portanto, a participação dos trabalhadores e, especificamente, dos comunicadores na gestão das organizações torna-se cada vez mais fundamental. Pode-se obter, por meio dela, um ambiente democrático e de compromisso entre os pares e entre estes e seus superiores, com deliberações colegiadas, podendo-se com isto reduzir a alienação e atenuar conflitos. A atuação dos profissionais de comunicação dentro das organizações tem um papel importante nessa integração, a começar pela interpretação do ambiente organizacional. O diagnóstico dos sentimentos e necessidades do público interno pode ajudar a desenvolver, implantar e manter sistemas de comunicação consensuados e adaptados à realidade $\mathrm{e}$, inclusive, adoçar os relacionamentos interpessoais com gotas de afetividade. Segundo Neves (2000, p. 195), “conhecer 'quemé quem', suas motivações, idiossincrasias, poder de fogo, é indispensável para a construção de estratégias e do plano de ação".

Comun. Inf., v. 4, n. 1/2, p.121-131, jan./dez. 2001 


\section{A gestão da comunicação interna}

Recomenda-se que a gestão da comunicação interna esteja calcada em elementos centrais da cultura administrativa, que se transformam na percepção de como fazer, com que métodos, de que modo e sob a orientação de quais valores. Considera-se boa gestão aquela que define objetivos claros, busca recursos humanos adequados às tarefas a serem executadas, empenha-se na motivação das pessoas, sabe buscar e compartilhar as estratégias mais adequadas para atingir os fins visados e, ainda, avalia e divide resultados.

Realizar tudo isso não é simples, quando se trata de administrar a comunicação interna. Existem muitas dificuldades, porque implica a gestão de pessoas, de processos e de resultados, o que impõe, de cara, alguns obstáculos. As instituições públicas historicamente não exercitam a preocupação com seus relacionamentos internos - relacionamentos que têm como complicador o fato de o público interno não ser composto por grupos homogêneos. Eles dividem-se em vários segmentos com características e objetivos, se não divergentes, no mínimo diferentes. Há grande diversidade de linguagem, de filosofia, de idade, de nível de escolaridade, de competências e de valores. Nessa diversidade residem os muitos entraves de relacionamento entre os níveis ascendente, descendente e horizontal.

Ressalte-se ainda que o modo de planejar e administrar a comunicação interna está diretamente ligado ao lugar ocupado pela comunicação e pelos profissionais dessa área nas administrações públicas, ou seja, seu poder de ação e de decisão para questões que dizem respeito à comunicação. A capacidade de gestão das dificuldades implica apostar em objetivos não vislumbrados e aproveitar, inclusive, as diferenças. Nessas circunstâncias, a tarefa do comunicador não é fácil. Implica romper com o isolamento de indivíduos e de "guetos", e com a desconfiança nos propósitos dos dirigentes e, mesmo, da instituição em si. São grandes as dificuldades na criação de ações que sejam efetivas para os ditos "ressentidos", que, nas palavras de Fortes (1999, p. 187), são "indivíduos que não estão naturalmente desencantados, mas estão irritados, bravos e profundamente ofendidos, no momento em que se entendem preteridos nas decisões que influenciam suas vidas".

As instituições públicas estão vivenciando momentos de insatisfação generalizada, em todos os níveis e serviços. Insatisfação com as

Comun. Inf., v. 4, n. 1/2, p.121-131, jan./dez. 2001 
políticas salariais adotadas, com os critérios de avaliação implantados, com a perda do sentimento de pertença e tantos outros. Exercitar o diálogo e direcioná-lo para o alcance da satisfação com o trabalho, com a convivência interna e com outros anseios são desafios dos comunicadores das instituições públicas no plano interno.

As necessidades e as respostas estão centradas nos níveis hierárquicos inferiores, mas são os dirigentes que habitualmente traçam as políticas e, em realidade, lideram as mudanças. Assim, crê-se que a eficaz gestão dos processos comunicativos internos é possível. Segundo Losada (2001, p. 4), pode-se alcançar essa eficácia com "la consecución de determinados acuerdos, compromissos y consensos, o puede favorecer, al menos, un sentimento de compreensión, de aceptación y fruto de ello, probablemente de implicación".

Muitas podem ser as estratégias utilizadas:

\section{- Planejamento dos relacionamentos:}

Planejar as formas de relacionamento interno torna-se fundamental. Para isso, começa-se segmentando e priorizando os interesses comuns entre a instituição e o corpo interno. Isso facilita criar, desenvolver e estabelecer consenso em torno da missão, dos objetivos e das finalidades da organização, tarefa que exige do comunicador um alto grau de conhecimento das formas de gestão, do público interno e da promoção da coesão interna. Lozada $(2001$, p. 6) enfatiza que essa coesão não pode ser obtida com uma comunicação qualquer, mas com aquela que leva em conta o seguinte princípio: "Comunicación es compartir algo, poner algo en común, significando ello no la acción mecánica o externa de realizar una tarea conjuntamente con otros, sino el percibir el mismo grado de conmoción interna emocional que el otro"

\section{- Organizar as informações:}

As informações precisas e habilmente organizadas são importantes no enfrentamento desses obstáculos. Há determinados aspectos que, por possibilitarem tomar boas decisões, devem ser considerados: o preestabelecimento do que, de quem e de quando, bem como do apoio de gerentes e de um plano de avaliação para medir o progresso do que estiver sendo executado.

Comun. Inf., v. 4, n. 1/2, p.121-131, jan./dez. 2001 
$\mathrm{Na}$ área da comunicação não basta ter idéias. Segundo Neves (2001, p. 208), "elas precisam ser organizadas, 'postas no papel', entendidas, clareadas, desafiadas, avaliadas, dissecadas, depuradas, peneiradas etc. As que sobrarem vão precisar de polimento antes de postas em execução. Depois, tudo isso deverá ser devidamente ordenado e cada coisa encaixada onde couber".

\section{- Planejamento global:}

Algumas administrações têm um planejamento que olha a instituição como um todo. Esse planejamento global geralmente cobre áreas e funções mais ligadas à produção, às finanças etc, mas comumente desleixa de questões relativas à imagem interna. Para que os servidores tenham compromisso com uma instituição e coesão em torno de objetivos comuns, é fundamental um planejamento que identifique necessidades. Isso permite aos comunicadores colaborar com os diretores e gerentes na busca de habilidades para formar equipes, para solucionar conflitos, para aconselhar, a fim de que se tornem, antes de mais nada, bons comunicadores (Corrado, 1994, p. 61).

\section{- Estratégias de comunicação apropriadas:}

Estratégias de comunicação adequadas e bem traçadas podem ampliar o leque de opções na construção, no estabelecimento de compromissos e na agregação de funcionários. Elas podem fomentar oportunidades advindas da comunicação administrativa e informal, por meio da ida aos lugares onde as pessoas trabalham, lancham etc. Isto contribui para:

. detectar os sinais não-verbais de confusão, de satisfação ou exaustão, de alegria ou tristeza;

. fazer alianças identificando quem pode ajudar, como e por que;

- definir o que pode e o que não pode ser feito;

. estabelecer estratégias de negociação e verificar quais os pontos que podem e os que não podem ser negociados;

- propor ações junto àqueles servidores que formam opinião;

. fortalecer as percepções positivas, ou seja, divulgar mais e melhor as coisas boas.

Comun. Inf., v. 4, n. 1/2, p.121-131, jan./dez. 200 ! 


\section{0}

A investigação, o questionamento e o planejamento são instrumentos importantes na construção de uma cultura de comunicação que leve o funcionário e as chefias a se educarem para o convívio no trabalho, para a participação e o envolvimento, para dar apoio, negociar e chegar a acordos. O planejamento das ações possibilita a construção de mensagens para públicos identificados, utilizando o meio de comunicação mais apropriado a eles e ao conteúdo; possibilita, ainda, a agregação de informações que contribuam para a avaliação do trabalho realizado e a realizar.

\section{Conclusão}

É importante que os profissionais de comunicação compreendam os valores e as crenças que, impregnadas na cultura das instituições públicas, norteiam o comportamento de todo o corpo interno - dirigentes e funcionários. O diagnóstico dos problemas estruturais e de relacionamento interno permite identificar dificuldades, ameaças, falhas e oportunidades de comunicação. Essa identificação possibilita criar um sistema de comunicação apropriado à cultura existente e, conseqüentemente, um modelo de gestão que garanta a consecução da missão da instituição.

O diagnóstico da comunicação permite o levantamento de dados originários da conduta administrativa, o questionamento dos procedimentos em voga e contribui na compreensão, análise e proposição de alternativas de comunicação capazes de alterar os relacionamentos hierárquicos estabelecidos e de transformar as ações e os procedimentos adotados.

A gestão da comunicação interna está diretamente ligada à capacidade de gestão das dificuldades internas, ao modo de planejar e ao lugar ocupado pela comunicação e seus profissionais nas instituições públicas. Neste momento de insatisfação generalizada no ambiente das instituições públicas, os comunicadores podem contribuir com diretores, chefes e todo o corpo de funcionários, no sentido de educá-los para o convívio no trabalho, para a participação e o envolvimento. As reflexões aqui apresentadas tencionam contribuir na conscientização dos profissionais de relações públicas e assessorias de imprensa das necessidades de comunicação demonstradas ao longo do texto.

Comun. Inf., v. 4, n. 1/2, p.121-131, jan./dez. 2001 


\begin{abstract}
Analyse the internal comunication of the organizations considering the changes occurred at the national and international level. Suggests important changes in the communication management process, strategic aspects, with the objective of making the development of a new pratical management in public organizations. Pinpoint the need for communication managers in public organizations to let go of currently used traditional bureaucratic models and promote an integrated communication at all levels of service. Probably the contribution that such professional could give to directors, managers and other employees at different levels would be to spread the awareness of the communication point raised in this text.

Keywords: interned communication, public management, changes alterations, public institutions.
\end{abstract}

\title{
Referências
}

BEUREN, Ilse Maria. Gerenciamento da informação: um recurso estratégico no processo de gestão empresarial. São Paulo: Atlas, 1998.

CABRERA, Carlos.; GAINO, Luciano. Administração estratégica de RH: uma abordagem sinérgica. Mercado Global, [s.1.],v. 16, n. 82, nov. 1989.

CORRADO, Frank M. A força da comunicação. São Paulo: Makron Books, 1994.

FORTES, Waldyr Gutierrez. Transmarketing: estratégias avançadas de Relações Públicas no campo do marketing. São Paulo: Summus, 1999.

GAINO, Luciano. O que o homem de marketing deve saber sobre Recursos Humanos. Mercado Global, [s.l.], v. 16, n. 82, nov. 1989.

LOSADA, José Carlos. Comunicación y significado para la participación interna en la universidad. In: CONGRESSO IBERO-AMERICANO DE COMUNICACIÓN, 1., 2001. Málaga. Anais... Málaga, 2001.

NEVES, Roberto de Castro. Comunicação empresarial integrada: como gerência imagem, questões públicas, comunicação simbólica e crises empresariais. Rio de Janeiro: Mauad, 2000.

OLIVEIRA Marco. Cultura organizacional. São Paulo: Nobel, 1998.

OSBORNE, David; GAEBLER, Ted. Reinventando o governo: como o espírito empreendedor está transformando o setor público. Brasília: MH Comunicação, 1998.

SROUR, Robert Henry. Poder, cultura e ética nas organizações. Rio de Janeiro: Campus, 1998.

Comun. Inf., v. 4, n. 1/2, p.121-131, jan./dez. $200^{1}$ 